\title{
The Role of Silicon in Preventing Appressorial Penetration by the Rice Blast Fungus
}

\author{
T. Hayasaka, H. Fujii, and K. Ishiguro
}

First author: Yamagata General Agricultural Research Center, Tsuruoka, Japan; second author: Yamagata University, Tsuruoka, Japan; and third author: National Agriculture Research Center for Tohoku Region, Morioka, 020-0198, Japan.

Current address of third author: National Agricultural Research Center, National Agriculture and Food Research Organization, Tsukuba, 3058666, Japan.

Accepted for publication 23 May 2008.

\begin{abstract}
Hayasaka, T., Fujii, H., and Ishiguro, K. 2008. The role of silicon in preventing appressorial penetration by the rice blast fungus. Phytopathology 98:1038-1044.

To test the hypothesis that silicon ( $\mathrm{Si}$ ) confers resistance against appressorial penetration of the rice blast fungus, the proportion of appressorial penetration into the leaf epidermis to total appressoria formed was compared among rice plants amended with various rates of silica gel to those plants nonamended. The amounts of Si in the youngest leaves were

rice leaves, the proportion of appressorial penetration was reduced by increasing amounts of silica gel applied and increased with the length of period after spray inoculation. Consequently, these results strongly support the hypothesis and suggest that $\mathrm{Si}$ in the leaf epidermis may confer resistance against appressorial penetration. Meanwhile, the number of lesions per leaf also decreased with the amount of Si applied, while only a certain part of penetrated appressoria could become sporulating susceptible lesions. This suggests that $\mathrm{Si}$ also confers physiological resistance against blast infection after the penetration.
\end{abstract} consistent with the amounts of silica gel applied to the rice plants. Relative Si levels on the adaxial surface of leaves as detected by energy dispersive X-ray analysis also increased with the amounts of silica gel applied. Based on light microscopic observation of the adaxial surface of
Additional keywords: Magnaporthe oryzae, mineral nutrition, physical fortification.
Rice (Oryza sativa L.) is one of the most important crops since it is used as the primary energy source by most world continents (8). Rice blast disease, caused by Magnaporthe oryzae Couch and Kohn (3) (anamorph, Pyricularia oryzae Cavara), is prevalent in most rice growing regions and may cause serious yield losses (25). Developing effective and affordable control measures of the disease is one of the most prioritized issues of rice production. These measures include breeding for durable disease resistance and improved soil nutrient management. The penetration and infection process of the blast fungus conidia on the leaf surface of rice plants has been well described and reviewed (13). Briefly, a germinated conidium forms an appressorium at the end of the germ tube. The appressorium strongly adheres to the surface of the rice epidermis (10). Appressoria are formed on various types of epidermal cells, and the penetration occurs through the epidermis and not into stomata or open wounds of the epidermis. Most fungal penetrations are followed by lesions that occur on motor cells, although never on guard cells. Appressoria do not form on silicified cells, and consequently, no penetration occurs on these cells. Various investigations hypothesize that the conidia must penetrate the epidermis by a mechanical force, although an alternative hypothesis that enzymes must soften the epidermal cell wall to help the infection hyphae penetrate into the epidermis can not be eliminated $(31,39)$. More recent studies demonstrate that a melanin layer extends around the entire cell wall of appressoria but not across the zone in contact with the substrate (11). Treatment of conidia with a melanin biosynthesis inhibitor, an effective protectant fungicide against rice blast, inhibits development of the

Corresponding author: K. Ishiguro; E-mail address: ishiguro@affrc.go.jp

doi:10.1094/PHYTO-98-9-1038

(C) 2008 The American Phytopathological Society melanin layer in the appressorial cell wall and prevents penetration of the host surface (37). Penetration into the surface of a polyester substrate, which is considered to be nonbiodegradable, required an elevated appressorial turgor pressure $(10,12)$. The pressure was estimated up to $8 \mathrm{MPa}(5)$. Ultrastructural observation of the appressorial penetration processes strongly suggested that the mechanical force should play an important role, as well as enzymatic modification of the cell wall of rice epidermis (16). All the findings strongly support the mechanical force hypothesis for penetration. However, a possibility that the fungus may also use enzymatic activity for penetration still remains (12).

Silicon ( $\mathrm{Si}$ ) is not usually classified as an essential element of higher plants (23). However, many plant species including those from the family Gramineae accumulate $\mathrm{Si}$ in their tissues (20). In rice plants, positive effects of Si have been observed $(2,20,32,39)$, and an Si transporter gene has been identified (22). Since silicate slag from a blast furnace was shown as a practical and affordable resource of Si (36), Si has been applied as an important element of fertilizer for rice crops $(21,24,35)$. In the early 20th century, many Japanese researchers demonstrated that application of various Si sources to rice plants increased resistance to blast (13). Since then, many subsequent studies have shown that application of $\mathrm{Si}$ is effective for suppressing rice blast disease $(4,9,33,34)$.

Until now, various hypotheses have been proposed to explain mechanisms by which Si confers resistance of rice plants against the blast disease (13). These hypotheses can be categorized into two types. One is the so called physiological resistance hypothesis in which $\mathrm{Si}$ must mediate some physiological changes of rice plants to confer disease resistance. Several recent studies provided evidence to support this hypothesis of Si-mediated physiological resistance (28-30). In the Arabidopsis-powdery mildew pathosystem, this hypothesis has been strongly supported (6). The other hypothesis is the physical barrier hypothesis in which $\mathrm{Si}$ must 
confer physical resistance against appressorial penetration. The physical barrier hypothesis may be further subdivided into two hypotheses. The first is called the silicified cell hypothesis in which decreased frequency of appressorial penetration with $\mathrm{Si}$ application to rice is attributed to increased frequency of silicified cells per unit area of leaf epidermis $(13,35)$. The second hypothesis is the cuticle-Si double layer puncture resistance hypothesis in which $\mathrm{Si}$ must confer penetration resistance of the epidermal surface against the appressorial penetration as a physical barrier $(13,31)$. The silicified cell hypothesis was not widely accepted, because appressoria did not form on silicified cells (13). Probably excess $\mathrm{Si}$ in rice plants may be accumulated in the silicified cells, and the frequency of the cells may be only an indicator to show that the rice plants have absorbed a considerable amount of $\mathrm{Si}$ (13). On the other hand, the cuticle-Si double layer puncture resistance hypothesis is consistent with several circumstantial findings. Puncture resistance measured by a torsion balance with a sharp needle tip, a Jolly balance, was proportional to the disease resistance assessed by inoculation tests $(13,31)$. Si was distributed just beneath the cuticle of rice leaf epidermis to form the cuticleSi double layer (39). Based on X-ray (15) and nuclear magnetic resonance (26) analyses, application of $\mathrm{Si}$ to the rice plants increased the level of $\mathrm{Si}$ in the cuticle-Si double layer together with decreasing the disease severity of leaf blast. However, the cuticle-Si double layer hypothesis lacks direct evidence at the present time. To obtain more convincing evidence, it is necessary to test whether application of Si to rice plants confers resistance against appressorial penetration by the blast fungus into rice leaf epidermal cells - the penetration resistance hypothesis. Once proven, this hypothesis would suggest that measures to enhance $\mathrm{Si}$ accumulation in the cuticle-Si double layer should fortify the leaf epidermis against penetration of the blast fungus, and consequently, affect the following infection processes.

The objective of this study was to test the penetration resistance hypothesis - application of Si to rice would confer resistance to leaf epidermal cells against appressorial penetration by $M$. oryzae. In this paper, the proportion of appressorial penetration into the leaf epidermal cell to total appressoria formed on the epidermis was compared between Si-treated and nontreated rice plants using light microscopy. In addition, Si levels at the surface layer of leaf epidermis, with X-ray analysis, were compared.

\section{MATERIALS AND METHODS}

Application of Si. Granular silica gel with a minimum $\mathrm{SiO}_{2}$ content of $95 \%$ (wt/wt) and $90 \%$ of the particle size ranging from 0.42 to $2.00 \mathrm{~mm}$ (Fuji Silysia Chemical, Tokyo, Japan) was used as a silicon source. The solubility of the silica gel after 3 days incubation in deionized water at $30^{\circ} \mathrm{C}$ was $20 \mathrm{mg} / \mathrm{liter}$, and the $\mathrm{pH}$ ranged from 4.5 to 5.5. Si-deficient volcanic soil from Yamagata Prefecture, Japan, was used as a standard soil. Silica gel at the rate of $0,2,4$, or $8 \mathrm{~g}$ and a slow-release fertilizer containing 0.4 0.23-0.17 g of N-P-K (ZEN-NOH, Tokyo, Japan) was mixed with $150 \mathrm{~g}$ of soil, which corresponds with the amount of soil for a seedling box used in this experiment.

Cultivation of plants. Before sowing, rice seeds (cv. Sasanishiki, which possesses Piks and Pia resistance genes but highly susceptible to compatible races of the rice blast fungus) were immersed in water at $15^{\circ} \mathrm{C}$ for 3 days and then incubated in water at $30^{\circ} \mathrm{C}$ for $24 \mathrm{~h}$. to enhance germination. Ten seeds were sown into each plastic seedling box $(35 \times 60 \times 105 \mathrm{~mm}$ in height/ width/depth), with the silica gel treatments described above. The emerged seedlings were flooded with water from the third-leaf growth stage in a greenhouse at 10 to $30^{\circ} \mathrm{C}$. The rice plants were kept until the eighth-leaf growth stage, and then inoculation and leaf sampling for $\mathrm{Si}$ were conducted.

Inoculation. A rice blast fungus isolate, Kyu 89-246 (race 003), virulent to Sasanishiki was used for inoculation. For inocu- lum preparation, the isolate was grown on oat meal agar in petri dishes at $25^{\circ} \mathrm{C}$. After mycelial mats had covered the surface of the agar plates, the mats were gently brushed with a tooth brush and then exposed to BLB lights (FL20S BL-B, Hitachi, Tokyo, Japan) for 2 days. The surface was then washed with sterilized distilled water and filtered with double layers of tissue paper to prepare the spore suspension. The concentration of conidia was adjusted to approximately $1 \times 10^{5}$ or $5 \times 10^{5}$ conidia $\mathrm{ml}^{-1}$ per plant (for experiments 1 and 2, respectively), and Tween 20 was added for a final concentration of $0.02 \%$ ( $\mathrm{vol} / \mathrm{vol})$.

For the spray inoculation, $4 \mathrm{ml}$ of suspension of conidia was sprayed onto the rice plants at the eighth-leaf growth stage with a glass chromatographic sprayer connected to an air compressor $(0.08 \mathrm{MPa})$. Sprayed rice plants were then kept in a moist chamber regulated at $25^{\circ} \mathrm{C}$ and $100 \%$ relative humidity for 8 to 20 h. After the treatment, the plants were rapidly dried with an electric fan and moved to the greenhouse.

Experimental design. In this study, two series of pot experiments were carried out. The first experiment (experiment 1) was conducted to test the effect of Si application to rice plants, as well as duration of wet period after spray inoculation on disease severity of leaf blast. The experiment design was a completely randomized factorial design with two factors and three replications. One factor was the amount of $\mathrm{Si}$ applied (with four treatments, as described above) and the other factor was the length of wet period after spray inoculation. Ten different wet periods were used $(8,9$, $10,11,12,13,14,16,18$, and $20 \mathrm{~h}$ ), during which period the relative humidity was kept above $99 \%$. At the end of the wet period, the rice plants were dried in the green house at room temperature. Each replication corresponded to eight rice plants in a seedling box.

The second experiment (experiment 2) was conducted to compare the proportion of penetrated sites by the fungus to total appressoria observed on the leaf epidermis of rice plants applied with various amounts of silica gel $(0,0.2,0.4$, and $0.8 \mathrm{~g}$ of silica gel per rice plant). Three seedling boxes, each containing 10 rice plants, were allocated for each level of silica gel application.

Assessment of disease severity. Seven days after inoculation, the number of typical sporulating susceptible lesions with large whitish spots or large eyespots with brown margins was counted on the eighth leaf blades of each plant. Eight plants were assessed in each replication, and the total number of lesions in each replication was $\log$-transformed $[\log (x+0.5)]$ for analysis of variance (ANOVA), since the number of leaf lesions per rice leaf has been empirically known to obey the log-normal distribution. General linear models (GLM) procedure of SAS software, version 9.1 (SAS Institute, Cary, NC), was used for this statistical analysis.

Observation of appressorial penetration. The cultivation method of rice plants was the same as described above. Conidia suspension $\left(5 \times 10^{5}\right.$ conidia $\left./ \mathrm{ml}\right)$ was sprayed onto the rice plants at the eighth-leaf growth stage, and the plants were kept in a moist chamber at $25^{\circ} \mathrm{C}$ for $20 \mathrm{~h}$. Subsequently, 70, 93, and $111 \mathrm{~h}$ after inoculation, the middle $6 \mathrm{~cm}$ length of the leaf blade of the eighth leaf of each rice plant was excised. Six leaf segments from three seedling boxes with the same treatment were collected for the observation.

The leaf segments were processed for microscopic observation according to the whole-leaf clearing and staining techniques (18) as follows. Immediately after obtaining leaf segments, they were immersed in $50 \mathrm{ml}$ of alcohol lacto-phenol (phenol, $5 \mathrm{~g}$; glycerin, $5 \mathrm{ml}$; lactic acid, $5 \mathrm{ml}$; distilled water, $5 \mathrm{ml}$; and ethanol, $40 \mathrm{ml}$ ) for 1 week to remove chlorophyll from the leaf tissues. The solution was replaced once, and these specimens were maintained in the solution until the next processing. Just before microscopy, the leaf segments were moved into vials containing $40 \mathrm{ml}$ of a $0.75 \%$ sodium chloride solution acidified by the addition of $0.5 \mathrm{ml}$ of $10 \%$ acetic acid, and the vials were heated at $95^{\circ} \mathrm{C}$ for $5 \mathrm{~min}$. The solution was then decanted, and the segments were 
dehydrated in a graded ethanol series (50, 70, 80, and 95\%) and two times in $100 \%$ ethanol under reduced pressure by a vacuum pump for $20 \mathrm{~min}$. The absolute alcohol was replaced with methyl salicylate. This renders the leaf segments completely transparent in a few minutes. For $5 \mathrm{~min}$, the leaf segments were stained with $0.2 \%$ crystal violet dissolved in methyl salicylate. Then, two rows of motor cells over $50 \mathrm{~mm}$ length per segment specimen (ca. $40 \mathrm{~mm}^{2}$ ) were arbitrarily examined by light microscopy.

When an appressorium was identified during the microscopic examination, the visible reaction of the epidermal cell/cells beneath the appressorium was discriminated between penetrated and unpenetrated states using a criterion based on the previous microscopic observations $(17,19,27)$ as follows. The penetrated state includes three categories: (i) cell granulation of the epidermal cell beneath the appressorium, (ii) cell browning of the epidermal cell beneath the appressorium, as well as the surrounding epidermal and parenchyma cells, and (iii) well-developed invading hyphae in the epidermal cell/cells. On the other hand, the nonpenetrated state is represented by the cell with no particular visible change from intact. The number of penetrated and unpenetrated cells in each specimen was counted. Data obtained from six specimens in the segment were totaled for statistical analysis. These data formed the two by four contingency table, and the Cochran-Armitage test for trend (1) was applied for the statistical analysis using FREQ procedure of SAS software.

$\mathrm{X}$-ray analysis of $\mathrm{Si}$ on leaf surface and cross section. Plants from the appressorial penetration experiment were prepared by excising the middle part of leaf blades of the eighth leaves (the uppermost completely extended leaves). Immediately after the excision, the segments were dehydrated in the same ethanol series as previously described for microscopic observation of appressorial penetration. The specimens were mounted on aluminum stubs by carbon double-faced adhesive tape, coated with gold, and examined by scanning electron microscopy (SEM, JED-2140; JEOL Ltd., Tokyo, Japan) at an accelerating voltage of $20 \mathrm{kV}$. This voltage resulted in a penetration depth of the electron beam into the leaf tissue at least $10 \mu \mathrm{m}$. Si deposition sites were determined with an energy-dispersive X-ray spectrometer (EDS) combined with the microscope. To observe the distribution pattern of $\mathrm{Si}$, carbon, and oxygen, secondary electron images and their corresponding X-ray elemental maps were acquired. X-rays were collected with a detector fixed at a take-off angle of $35^{\circ}$, and their spectra were recorded during a process time of $100 \mathrm{~s}$ per point.

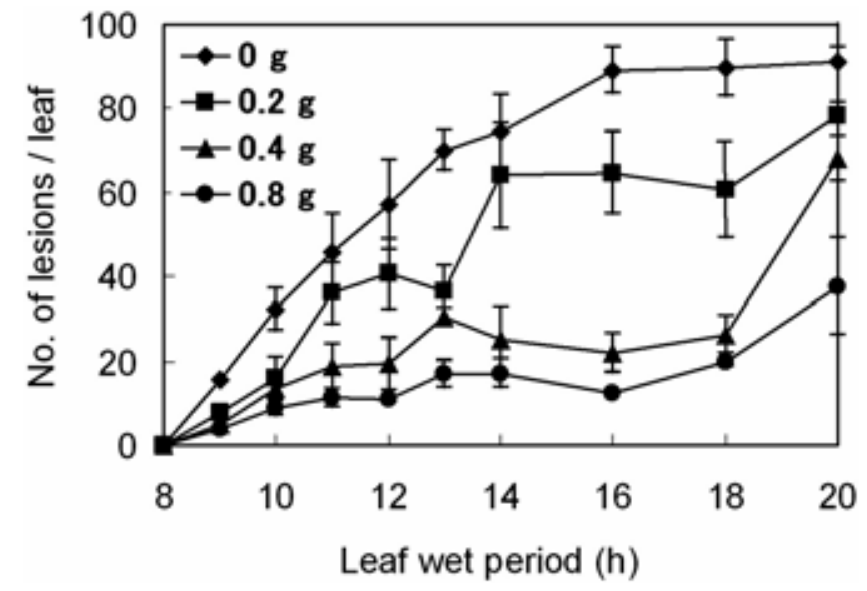

Fig. 1. Relationship between leaf wet period after spray inoculation and number of leaf blast lesions on cv. Sasanishiki as influenced by various rates of silica gel. The number of susceptible blast lesions at the eighth-leaf growth stage was counted 7 days after inoculation. Each data point represents the mean number of susceptible blast lesions per leaf from three replications (each replicate consists of eight leaves). Vertical bars represent one standard error of the mean.
$\mathrm{Si}$ levels in the adaxial surface of rice leaves were quantified by surface analysis (point analysis on $256 \times 256$ pixels) with EDS. One site per leaf surface was randomly selected, and nine leaves for each application level of silica gel were probed for $\mathrm{X}$-ray emission at $\times 1,000$ magnification. An elemental peak in energy of $1.74 \mathrm{keV}$ in the $\mathrm{X}$-ray spectrum was regarded as the characteristic X-ray signal for Si. X-ray intensities of $\mathrm{Si}$ were recorded in counts per second (CPS). The relative levels of $\mathrm{Si}$ were expressed as a ratio of Si CPS of a specimen to that of standard $\mathrm{Si}$.

Quantitative analysis of Si in whole leaf tissue. In all experiments in this study that consisted of different application levels of silica gel to rice plants, Si contents of rice leaf tissues in various application levels of silica gel were determined. Just before inoculation, leaf blades of the eighth leaf of one or two rice plants were collected from each seedling box. Regardless of the replication, leaves from rice plants with the same application level were put together for the following quantitative determination. These leaf samples were air-dried at $70^{\circ} \mathrm{C}$ for 3 days and then ground to a fine powder in a mortar. The samples were dissolved by hydrogen peroxide and sulfuric acid. Total Si content was determined by the gravimetric method after dry combustion (14).

\section{RESULTS}

Effect of Si application on disease resistance of rice plants against leaf blast. Disease severity of leaf blast, assessed as the number of lesions per leaf, decreased with increasing rate of silica gel applied to the rice plants in experiment 1 (Fig. 1). This tendency was observed for all wet period durations between 8 and $20 \mathrm{~h}$ after spray inoculation. Leaf blast severity increased as the length of wet period increased for all rates of silica gel applied (Fig. 1). ANOVA indicated that the effect of silica gel applied and the effect of the wet period on the number of leaf blast lesions were both statistically significant $(P<0.0001)$, and the interaction between these two factors were also significant $(P=0.0004)$.

The amount of $\mathrm{Si}$ contained in the eighth leaf increased with increasing rates of applied silica gel to the rice plants (Fig. 2A) and was consistent for all the experiments (data not shown). Different rates of Si application had no significant effect on leaf area (the mean over all treatments was $52.7 \mathrm{~cm}^{2}$ ).

Localization and quantification of $\mathrm{Si}$ deposition in rice leaves by SEM/EDS. With regard to SEM/EDS observation of cross sections of the youngest rice leaves, Si mainly accumulated on the surface of leaves and was infrequently distributed inside the leaf tissue, whereas carbon and oxygen elements were distributed more uniformly in the leaf tissue (Fig. 3). In Figure 3C, bright images on the background came from the carbon doublefaced adhesive tape that mounted the specimen on the stub.

SEM images of the adaxial side of rice leaf surface showed no clear morphological differences between a rice plant treated with silica gel and an untreated one (Fig. 4A and B). The leaf surface of both rice plants had numerous wartlike protuberances, typically seen on the adaxial side. However, the corresponding EDS images of Si element compared with the SEM images (Fig. 4C compared with Fig. 4A and Fig. 4D compared with Fig. 4B, respectively) demonstrated a significant difference in $\mathrm{Si}$ content on the leaf surface between Si-treated and nontreated plants. The brighter image observed in Figure 4D compared with Figure 4C indicates that leaf surface of Si-treated plants contains more Si than untreated plants. Quantitative analysis of the X-ray spectrum detected by EDS corresponding to Figure 4C and D were shown in Figure 4E and F, respectively. Evidently, the Si peak, as well as the $O$ peak, of the silica gel-treated rice plant was much higher than that of the untreated one.

Weight concentration of $\mathrm{Si}(\%)$ detected by EDS on the youngest leaf surface of rice plants increased with the amount of silica gel applied to the plants (Fig. 2B). Rice plants that received 
$0.8 \mathrm{~g}$ of silica gel were approximately five times greater for $\mathrm{Si}$ in the leaf surface compared with the controls.

Effect of $\mathrm{Si}$ application on appressorial penetration. The mean density of appressoria on motor cells was $332 \mathrm{~cm}^{-2}$, with the standard deviation $69.1 \mathrm{~cm}^{-2}$. ANOVA showed that there were no significant differences in frequency of appressoria forming due to the rate of silica gel applied $(P=0.253)$, the length of wet period (relative humidity over 99\%) after spray inoculation $(P=$ $0.685)$, and replication of the seedling boxes $(P=0.451)$.

Some appressoria penetrated the epidermal cells of the rice leaves. The mean number of appressoria observed under the same amount of silica gel applied and the same length of wet period after inoculation was 2,391.2 with the standard deviation 258.5. The proportion of penetrated appressoria to total appressoria was
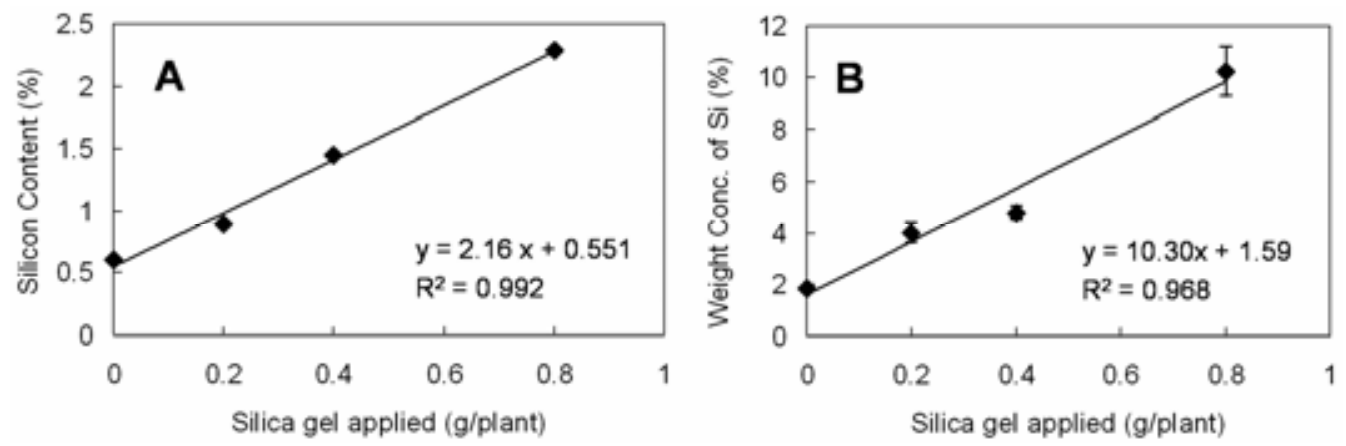

Fig. 2. Relationship between rates of silica gel applied $(x)$ and silicon content of the youngest fully extended leaves at the eighth-leaf growth stage of rice cv. Sasanishiki $(y)$. A, Each data point represents the silicon content (wt/wt) of the leaf blades. The leaves of one or two rice plants were sampled from each of three replicates, and all the leaves in the same treatment were put together before the quantitative determination. B, Each data point represents the mean weight concentration of $\mathrm{Si}(\%)$ at the adaxial surface of the leaves from three replicates determined with an energy-dispersive X-ray spectrometer (each replication consists of three leaf specimens). Vertical bars represent one standard error of the mean.

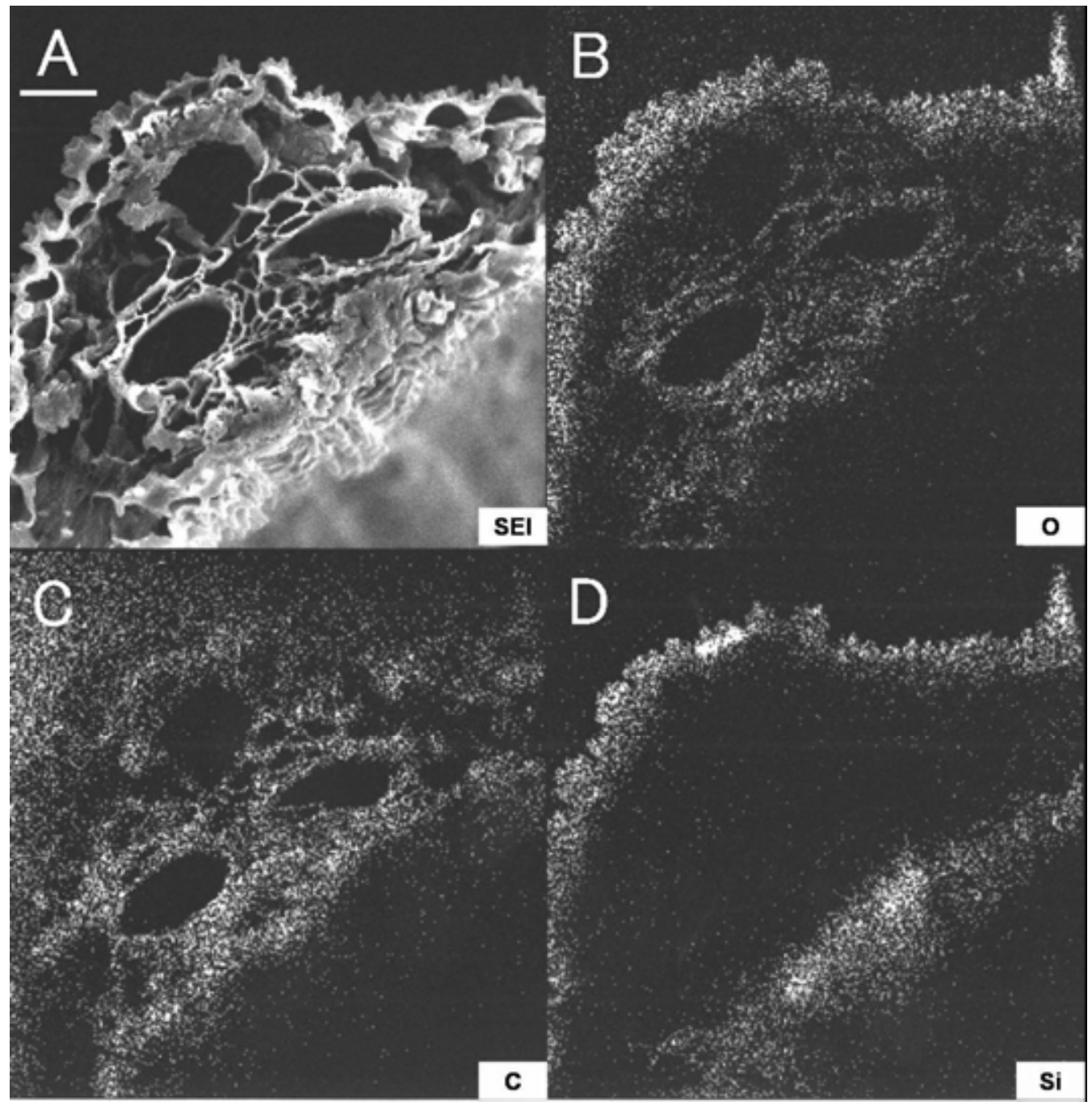

Fig. 3. A, A scanning electron micrograph and $\mathbf{B}$ to $\mathbf{D}, \mathbf{X}$-ray maps of a cross section of cv. Sasanishiki at the eighth-leaf stage. A, B, C, and $\mathbf{D}$ are all displayed on the same scale. $B a r=20 \mathrm{~m}$. The bright images in $\mathbf{B}$ to $\mathbf{D}$ are due to a large amount of each element $(\mathbf{B}$, oxygen; $\mathbf{C}$, carbon; and $\mathbf{D}$, silicon) being deposited at the high concentration. 


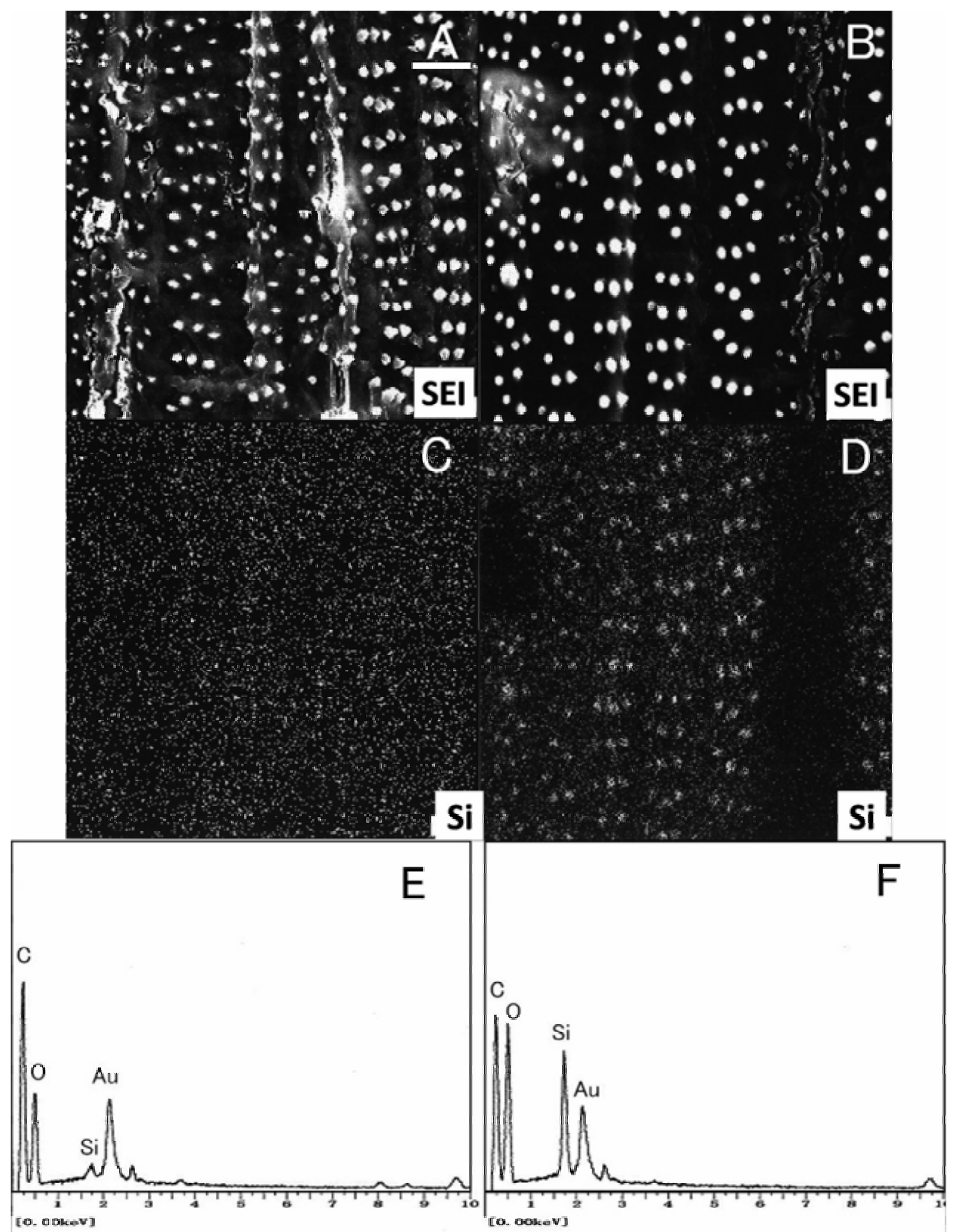

Fig. 4. A and B, Scanning electron micrographs, $\mathbf{C}$ and $\mathbf{D}$, silicon X-ray maps, and $\mathbf{E}$ and $\mathbf{F}$, X-ray spectra of adaxial side of rice (cv. Sasanishiki) leaf surfaces. A and $\mathbf{B}$, The scanning electron microscopy images of leaf epidermis of a silicon nontreated and treated plant, respectively. $\mathbf{C}$ and $\mathbf{D}$, The X-ray silicon maps of $\mathbf{A}$ and $\mathbf{B}$, respectively. Bar $=20 \mathrm{~m}$. A, B, C, and $\mathbf{D}$ are all displayed on the same scale. White dots in $\mathbf{C}$ and $\mathbf{D}$ indicate silicon deposition at their corresponding positions of the specimen; $\mathbf{E}$ and $\mathbf{F}$, The X-ray spectra of $\mathbf{A}$ and $\mathbf{B}$, respectively. The gold peaks in $\mathbf{E}$ and $\mathbf{F}$ came from the gold coating of specimens.

reduced with an increasing rate of silica gel applied to rice, regardless of the length of wet period after inoculation (Fig. 5), and was statistically significant based on the Cochran-Armitage test $(P<0.001)(1)$. The proportions of penetrated appressoria to total appressoria also increased with the length of the wet period regardless of the rate of silica gel applied (Fig. 5), and was also statistically significant based on the Cochran-Armitage test $(P<$ 0.001).

Difference in $\mathrm{Si}$ sensitivity between appressorial penetration and lesion development. Both the number of lesions per leaf and 
the proportion of penetrated appressoria decreased with the amount of Si applied (Figs. 1 and 5). However, only a relatively small portion of the penetrated appressoria developed to become sporulating lesions (approximately 10 to $65 \%$ depending on experiment). As Si amount increased from 0 to $0.8 \mathrm{~g}$, the proportion of appressoria that penetrated the epidermis after $111 \mathrm{~h}$ decreased 5-fold (Fig. 5), while the proportion of penetration that progressed to sporulating lesions fell only 2.5 -fold (Fig. 1).

\section{DISCUSSION}

Many earlier studies have reported that application of Si materials, including silica gel, silicate slag, or calcium silicate, to rice plants increased $\mathrm{Si}$ content in the rice tissues $(4,13,36)$ and mitigated the severity of rice blast $(4,9,13,33,34)$. Our present study further confirms these results (Figs. 1 and 2A). Other earlier studies also have shown that $\mathrm{Si}$ was mainly distributed on the surface area of the leaf epidermis $(15,39)$, and that Si application to the rice plants made the $\mathrm{Si}$ layer in the leaf epidermis much denser $(15,26)$. Our present study based on EDS analysis also confirms this observation (Figs. 3 and 4). The penetration depth of the electron beam of this EDS was at least $10 \mu \mathrm{m}$. Previous studies $(15,39)$ indicated that the Si layer, or the cuticle-Si double layer (39), in the rice leaf epidermis developed approximately $5 \mu \mathrm{m}$ below the leaf surface. Consequently, our quantitative analysis could evaluate the density of the Si layer, concluding that application of $\mathrm{Si}$ to rice plants increased the $\mathrm{Si}$ density of the $\mathrm{Si}$ layer in the leaf epidermis. In an earlier study, Ishiguro (13) and Sakamoto (31) showed that application of Si to the rice plants conferred physical resistance of epidermal cells against puncture with a sharp needle. However, the puncture resistance does not necessarily represent the resistance against appressorial penetration of the blast fungus, as discussed by Ishiguro (13) and Sakamoto (31). As such, our results (Fig. 5) probably represent the first evidence to support the hypothesis that application of $\mathrm{Si}$ to rice plants confers resistance against appressorial penetration of the blast fungus directly into the leaf epidermal cells of rice.

While the role of the Si layer in the epidermis of rice leaves is still uncertain in a strict sense, there have been several lines of evidence to suggest that the Si layer plays an important role as a physical barrier against appressorial penetration. Our data (Figs. 2B and 4) confirm that $\mathrm{Si}$ application increased density of $\mathrm{Si}$ in the Si layer of the epidermis of rice leaves $(15,26)$. The higher peak of $\mathrm{O}$, as well as that of $\mathrm{Si}$, in an Si-treated plant compared with those in nontreated plants (Fig. 4E and F) may imply that $\mathrm{Si}$ in the Si-treated plant was deposited on the epidermis as a form of $\mathrm{SiO}_{2}$. In our present study, application of silica gel to the rice plants not only increased the density of the Si layer in the leaf epidermis (Fig. 2B) but also decreased the frequency of appressorial penetration by the blast fungus (Fig. 5). This fact does not necessarily prove a cause-and-effect relationship between the denser Si layer and the less frequent appressorial penetration. However, on the rice leaves with the denser Si layer, appressorial penetration of the blast fungus required a longer wet period after spray inoculation (Fig. 1) and a longer time to complete the appressorial penetration (Fig. 5). This held true even if the wet period was for the same time interval $(20 \mathrm{~h})$ for the rice plants that possessed a denser Si layer. As such, the results obtained this study strongly suggest the involvement of physical resistance, but further studies are necessary to better confirm the actual mechanism of resistance against appressorial penetration, especially given the very different assessments of the turgor pressure that is required for an appressorium to penetrate the rice epidermis, which differ by four orders of magnitude $(5,7,13,31)$.

One important observation made here was that only a relatively small portion of the penetrated appressoria develops to become sporulating lesions (approximately 10 to $65 \%$ depending on experiment). Both the number of lesions per leaf and the proportion

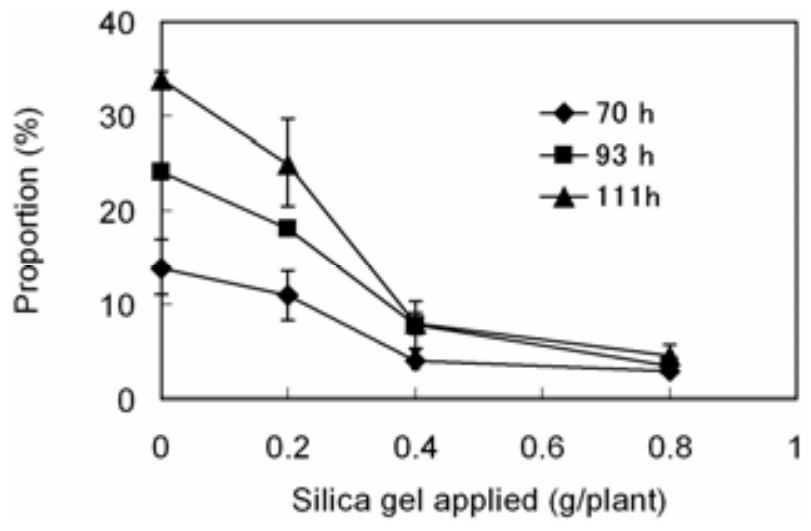

Fig. 5. Relationship between proportions of penetrated appressoria to total appressoria of Magnaporthe oryzae observed in rice motor cells and rate of silica gel. Microscopic observations were determined at 70, 93, and $111 \mathrm{~h}$ after inoculation. Each data point represents the mean proportion from three replicates (each replicate consists of six leaves). Vertical bars represent one standard error of the mean.

of penetrated appressoria decreased with the amount of Si applied (Figs. 1 and 5). It has been known that some physiological plant cell defense responses in rice plants can be triggered before appressorial penetration of the blast fungus occurs $(29,38)$. In that case, a direct effect of $\mathrm{Si}$ in increasing the time lag between the start of the plant defense responses and appressorial penetration would allow a longer period during which physiological resistance mechanisms could be induced. In that sense, there may be positive interactions between physical resistance conferred by $\mathrm{Si}$ application and physiological mechanisms of resistance, although it is not easy to establish this hypothesis only from the data obtained here.

The final goal of our study was to elucidate how Si application to rice plants reduces the severity of rice blast. Within the present study, however, we can only conclude that application of silica gel to the rice plants certainly reduces the frequency of appressorial penetration of the blast fungus, as well as simultaneously reduces the severity of leaf blast. Between these two facts, there are still some gaps of knowledge. Future studies are warranted in trying to fully comprehend the role of $\mathrm{Si}$ in rice blast resistance.

\section{ACKNOWLEDGMENTS}

We acknowledge the invaluable statistical analyses conducted by the Information System Division in the Agriculture, Forestry and Fisheries Research Council Secretariat, Tsukuba Office of the Ministry of Agriculture, Forestry and Fisheries of Japan.

\section{LITERATURE CITED}

1. Agresti, A. 1996. An introduction to categorical data analysis. Wiley, New York.

2. Ando, H., Kakuda, K., Fujii, H., Suzuki, K., and Ajiki, T. 2002. Growth and canopy structure of rice plants grown under field conditions as affected by Si application. Soil Sci. Plant Nutr. 48:429-432.

3. Couch, B. E., and Kohn, L. E. 2002. A multilocus gene genealogy concordant with host preference indicates segregation of a new species, Magnaporthe oryzae, from M. grisea. Mycologia 94:683-693.

4. Datnoff, L. E., Snyder, G. H., Raid, R. N., and Jones, D. B. 1991. Effect of calcium silicate on blast and brown spot intensities and yields of rice. Plant Dis. 75:729-732.

5. De Jong, J. C., McCormack, B. J., Smirnoff, N., and Talbot, N. J. 1997. Glycerol generates turgor in rice blast. Nature 389:244-245.

6. Fauteux, F., Chain, F., Belzile, F., Menzies, J. G., and Belanger, R. R. 2006. The protective role of silicon in the Arabidopsis-powdery mildew pathosystem. Proc. Natl. Acad. Sci. USA 103:17554-17559.

7. Goriely, A., and Tabor, M. 2006. Estimates of biomechanical forces in Magnaporthe grisea. Mycol. Res. 110:755-759.

8. Greenland, D. J. 1997. The sustainability of rice farming. CAB International, Wallingford, UK and IRRI, Los Banos, Philippines. 
9. Hayasaka, T., Fujii, H., and Namai, T. 2005. Silicon content in rice seedling to protect rice blast fungus at the nursery stage. J. Gen. Plant Pathol. 71:169-173.

10. Howard, R. J. 1994. Cell biology of pathogenesis. Pages 3-22 in: Rice Blast Disease. R. S. Ziegler, S. Leong, and P. S. Teng, eds. CAB International, Wallingford, UK and IRRI, Los Banos, Philippines.

11. Howard, R. J., and Ferrari, M. A. 1989. Role of melanin in appressorium function. Exp. Mycol. 13:403-418.

12. Howard, R. J., Ferrari, M. A., Roach, D. H., and Money, N. D. 1991. Penetration of hard substrates by a fungus employing enormous turgor pressure. Proc. Natl. Acad. Sci. USA 88:11281-11284.

13. Ishiguro, K. 2001. Review of research in Japan on the roles of silicon in conferring resistance against rice blast. Pages 277-291 in: Silicon in Agriculture. L. E. Datnoff, G. H. Snyder, and G. H. Korndörfer, eds. Elsevier, Amsterdam, The Netherlands.

14. Kilmer, V. J. 1965. Silicon. Pages 959-962 in: Methods of Soil Analysis. Part 2. C. A. Black, ed. Am. Soc. Agron., Madison, WI.

15. Kim, S. G., Kim, K. W., Park, E. W., and Choi, D. 2002. Silicon-induced cell wall fortification of rice leaves: A possible cellular mechanism of enhanced host resistance to blast. Phytopathology 92:1095-1103.

16. Koga, H. 1994. Hypersensitive death, autofluorescence, and ultrastructural changes in cells of leaf sheaths of susceptible and resistant nearisogenic lines of rice $\left(\mathrm{Pi}-\mathrm{z}^{\mathrm{t}}\right)$ in relation to penetration and growth of Pyricularia oryzae. Can. J. Bot. 72:1463-1477.

17. Koga, H., Dohi, K., Nakayachi, O., and Mori, M. 2004. A novel inoculation method of Magnaporthe grisea for cytological observation of the infection process using intact leaf sheaths of rice plants. Physiol. Mol. Plant Pathol. 64:67-72.

18. Koga, H., and Kobayashi, T. 1980. A whole-leaf clearing and staining technique to observe the invaded hyphae of blast fungus and host response in rice leaves. Ann. Phytopathol. Soc. Jpn. 46:679-681.

19. Koga, H., and Kobayashi, T. 1982. Comparison of the early infection process of Pyricularia oryzae Cav. in rice leaves of compatible and incompatible combinations. Ann. Phytopathol. Soc. Jpn. 48:506-513.

20. Ma, J. F., Miyake, Y., and Takahashi, E. 2001. Silicon as a beneficial element for crop plants. Pages 17-39 in: Silicon in Agriculture. L. E. Datnoff, G. H. Snyder, and G. H. Korndörfer, eds. Elsevier, Amsterdam, The Netherlands.

21. Ma, J. F. and Takahashi, E. 2002. Soil, Fertilizer, and Plant Silicon Research in Japan. 1st ed. Elsevier Science, Amsterdam, The Netherlands.

22. Ma, J. F., Tamai, K., Yamaji, N., Mitani, M., Konishi, S., Katsuhara, M., Ishiguro, M., Murata, Y., and Yano, M. 2006. A silicon transporter in rice. Nature 440:688-691.

23. Marschner, H. 1995. Beneficial mineral elements. Pages 405-435 in: Mineral Nutrition of Higher Plants. 2nd ed. Academic Press, San Diego, CA.

24. Ohta, M., Kobayashi, K., and Kawaguchi, U. 1953. Studies on silicates for fertilizer use. Memoirs Fac. Liberal Arts Educ. Yamanashi Univ.
4:351-358.

25. Ou, S. H. 1985. Rice Diseases. 2nd ed. Commonwealth Mycological Institute, Kew, England.

26. Park, J.-J., Kim, K.-W., Park, T.-J., Park, E.-W., and Kim, Y. 2006. Solidstate NMR spectroscopy of silicon-treated rice with enhanced host resistance against blast. Analytical Sci. 22:645-648 .

27. Peng, Y. L., and Shishiyama, J. 1989. Timing of a cellular reaction in rice cultivars associated with differing degrees of resistance to Pyricularia oryzae. Can. J. Bot. 68:2704-2710.

28. Rodrigues, F. A., Benhamou, N., Datnoff, L. E., Jones, J. B., and Belanger, R. R. 2003. Ultrastructural and cytochemical aspects of siliconmediated rice blast resistance. Phytopathology 93:535-546.

29. Rodrigues, F. A., Jurick, W. M., Datnoff, L. E., Jones, J. B., and Rollins, J. A. 2005. Silicon influences cytological and molecular events in compatible and incompatible rice-Magnaporthe grisea interactions. Physiol. Mol. Plant Pathol. 66:144-159.

30. Rodrigues, F. A., McNally, D. J., Datnoff, L. E., Jones, J. B., Labbe, C., Benhamou, N., Menzies, J. G., and Belanger, R. R. 2004. Silicon enhances the accumulation of diterpenoid phytoalexins in rice: A potential mechanism for blast resistance. Phytopathology 94:177-183.

31. Sakamoto, M. 1968. Studies on resistance of rice to rice blast disease. (in Japanese) Pages 1-139 in: Jubilee Publication in Commemoration of Sixtieth Birthday of Prof. Masayuki Sakamoto. The Organization for Jubilee Publication in Commemoration of Sixtieth Birthday of Prof. Masayuki Sakamoto, Sapporo, Japan.

32. Savant, N. K., Snyder, G. H., and Datnoff, L. E. 1997. Silicon management and sustainable rice production. Adv. Agron. 58:151-199.

33. Seebold, K. W., Datnoff, L. E., Correa-Victoria, F. J., Kucharek, T. A., and Snyder, G. H. 2000. Effect of silicon rate and host resistance on blast, scald, and yield of upland rice. Plant Dis. 84:871-876.

34. Seebold, K. W., Kucharek, T. A., Datnoff, L. E., Correa-Victoria, F. J., and Marchetti, M. A. 2001. The influence of silicon on components of resistance to blast in susceptible, partially resistant, and resistant cultivars of rice. Phytopathology 91:63-69.

35. Snyder, G. H., Jones, D. B., and Gascho, G. J. 1986. Silicon fertilization of rice on Everglades Histosols. Soil Sci. Soc. Am. J. 50:1259-1263.

36. Suzuki, H., and Shigematsu, K. 1952. Slag as an internal preventive chemical for rice blast disease. (in Japanese) Shokubutu Boeki 6:294-297.

37. Woloshuk, C. P., Sisler, H. D., Tokousbalides, M. C., and Dutky, S. R. 1980. Melanin biosynthesis in Pyricularia oryzae: Site of tricyclazole inhibition and pathogenicity of melanin deficient mutants. Pestic. Biochem. Physiol. 14:256-264.

38. Xu, J. R., Staiger, C. J., and Hamer, J. E. 1998. Inactivation of the mitogen-activated protein kinase Mpsl from the rice blast fungus prevents penetration of host cells but allows activation of plant defense responses. Proc. Natl. Acad. Sci. USA 95:12713-12718.

39. Yoshida, S. 1965. Chemical aspects of the role of silicon in physiology of the rice plant. Bull. Natl. Inst. Agric. Sci. Ser. 15:1-58. 